\title{
Embryonic and Placental Damage Induced by Maternal Autoimmune Diseases - What Can We Learn from Experimental Models
}

\author{
Zivanit Ergaz ${ }^{1}$ and Asher Ornoy ${ }^{2}$ \\ ${ }^{1}$ Laboratory of Teratology, Israel Canada Institute of Medical Research \\ Hebrew University Hadassah Medical School, Jerusalem \\ Department of Neonatology, Hadassah-Hebrew University Hospital \\ Mount Scopus, Jerusalem \\ ${ }^{2}$ Laboratory of Teratology, Israel Canada Institute of Medical Research, Hebrew University \\ Hadassah Medical School, Jerusalem, Israel and Israeli Ministry of Health
}

Israel

\section{Introduction}

Autoimmune diseases may have an adverse effect on reproduction and pregnancy outcome. Systemic Lupus Erythematosus (SLE) is associated with a wide variety of antibodies to different cell body components, mostly antiphospholipid antibodies. These are a heterogeneous group of antibodies that bind to negatively charged phospholipids and/or serum phospholipid binding proteins. Antiphospholipid syndrome (APLs) may occur as primary APLs or in association with autoimmune diseases. During normal pregnancy maternal immunity and hormones allow fetal survival, but when these mechanisms are impaired it may have a detrimental effect on the fetus. Pregnancies in women with APLs can be complicated by a high rate of pregnancy loss, pre-eclampsia, fetal growth restriction, prematurity and fetal distress. Disease flare during pregnancy predicts adverse fetal outcome (Kwok et al., 2011). The mechanisms underlying the recurrent abortions and fetal loss among women suffering from SLE are not completely elucidated. Thrombotic placental events may explain only some of the miscarriages. In vitro cell culture of placental trophoblast cell lines with IgG from patients suffering from APLs showed that APLs/ anti- $\beta 2$-glycoprotein I antibodies / anti- $\beta 2$ globulin antibodies might disrupt the annexin coverage of thrombogenic anionic surfaces on the trophoblast and endothelial cell monolayers and lead to Factor $X$ and prothrombin activation (Rand et al., 1997). However histopathological findings suggestive of thrombosis cannot be detected in the majority of the placentas from women suffering from APLs (Levy et al., 1998, Meroni et al., 2008). It has been suggested that antiphosholipids may be responsible for a local acute inflammatory response mediated by complement activation and neutrophil infiltration that eventually leads to fetal loss. Circulating antiphospholipid antibodies occurring at about $40 \%$ of SLE patients are associated with fetal loss. Some investigators regard APLs as a marker for recurrent abortions and not necessarily as their primary cause. Lupus anticoagulants, anticardiolipin and anti- $\beta 2$-glycoprotein I 
antibodies are typically found among the patients. Complement activation was shown to play a role in antiphospholipid antibody - mediated fetal loss associated with inflammatory process, when $\mathrm{C} 4 \mathrm{~d}$, a degradation product of $\mathrm{C} 4$ was demonstrated in human placenta of SLE patients (Cohen et al., 2011), as well as diminished number of T regulatory cells, associated with pregnancy loss and pre-eclampsia (Tower et al., 2011). Circulating microparticles that expose phospholipids in the outer membrane and induce coagulation via tissue factor have been associated with lupus anticoagulants and poor obstetric outcome (Alijotas-Reig et al., 2009). Other reports indicate that enhanced oxidative stress could be linked to autoimmune diseases; however, there is lack of data about anti oxidant status of the placenta and embryos during pregnancy in women suffering from autoimmune diseases.

\section{The role of experimental animal studies in evaluation of pregnancy complications among women suffering from autoimmune diseases}

As more than one mechanism of pathogenesis exists for fetal damage in autoimmune diseases, experimental animal models can be used to isolate the different causative effects. Evaluation of the role of different antibodies and molecules can be obtained by direct injection or induction of antibodies production in the pregnant animals and evaluation of the resultant effect on the embryos and fetuses. In such case the effect is evaluated in normal animals rather than being secondary to an autoimmune disease.

Previous published studies revealed fetal damage induced by various antibodies. A smaller litter size was demonstrated after the injection to pregnant BALB/C mice with a human cytomegalovirus -peptide-induced monoclonal antiphospholipid (Gharavi et al., 2004). Fetal heart block and bradycardia were evidenced in a murine model as a result of maternal autoantibodies to Ro and La antigen induced by maternal immunization (Suzuki et al., 2005). In addition maternal immunization with DNA memitope in mice led to the induction of autoantibodies that bind DNA and the N-methyl-D-aspartate receptor in the maternal circulation leading to increased neocortical cell death in the fetal brain and subsequent delayed acquisition of neonatal reflexes and cognitive impairments in the adult offspring. In this model the antibodies that were detected in the fetal neocortex outside of blood vessels evidenced their transport through fetal circulation until binding to the fetal brain (Lee et al., 2009). We previously found that the immunization of BALB / C mice with mouse laminin-1 was followed by the development of anti-laminin-1 antibodies. A double fetal resorption rate and lower fetal and placental weight was found in the laminin-1 immunized group compared with controls. Resorption rate was highest in the subgroup of animals with very high levels of anti-laminin-1 (Matalon et al., 2003). Other molecules were also found to have direct embryotoxic effects. The injection of a low-molecular weight fraction of boiled human serum containing antiphospholipid antibodies that had been obtained from women with antiphospholipid syndrome to pregnant rats at day 5 - 6 of pregnancy resulted in increased embryonic apoptosis 2 to 4 hours after the injection (Halperin et al., 2008).

\section{In vitro systems to evaluate sera toxicity in autoimmune diseases}

To try to evaluate the different mechanisms that lead to poor obstetric outcome we practiced three in vitro systems that use sera obtained from patients suffering from autoimmune diseases and recurrent abortions as culture media. 


\subsection{In vitro development of pre-implantation mice embryos in culture}

Mouse blastocysts obtained from the uterine horns before implantation at 3.5 days of gestation can be cultured for up to 10 days and reach the developmental stage equivalent of 9.5 to 10 days of gestation in utero, or one-half of the total gestational period. At that early somite stage, the blood circulation in the yolk sac is not yet established and the anterior neuropore is open. The limb buds and the primordia of the lung, liver, and pancreas are not yet present (Chen \& Hsu, 1982).

The technology in brief: Female mice are treated with gonadotropins followed $48 \mathrm{~h}$ later by Human Chorionic Gonadotropin in order to cause super-ovulation. The mice are mated with males and insemination is verified the following morning by the finding of a copulation plug in the vagina (day 0). Late morula-early blastocyst stages are obtained by flushing the uterine horns with culture medium 3 days after mating. Embryos are removed from several mice, pooled in an embryological watchglass, washed and transferred to fresh medium. A group of 8-10 embryos are placed in drops with Eagle's medium supplemented with $50 \%$ or $80 \%$ human serum. L Glutamine is added to the medium in a concentration of $2 \mathrm{mM} / \mathrm{cc}$. Embryos are cultured in a humidified atmosphere in unaerobic conditions under paraffin drops. They are checked before incubation, after 24 and 72 hours or other incubation times under an inverted microscope to determine the developmental stage. The parameters used as criteria for assessing the rate of development and differentiation of embryos are namely, hatching of blastocysts from the zona pellucida, their adhesion to the substratum, and outgrowth and spreading on the surface (Abir et al., 1990).

Using this method, one can examine direct effects of the sera from women with recurrent abortions on early pre-implantation embryos.

\subsection{In vitro development of early somite stage rat embryos in culture}

The early somite rat embryo culture allows the investigation of the embryotoxicity of various teratogens in face of the difficulty to perform studies on mammalian embryos while in utero (New et al., 1976). It is an in vitro method to evaluate teratogenicity of various chemicals (i.e. different drugs and chemicals) as the tested compounds are added to the culture medium and the embryos cultured during organogenesis (New et al., 1976). The various agents can be evaluated either individually or in combination. Adverse embryonic outcomes (malformations or embryolethality) were shown to be directly related to the serum concentration of the compound being tested and can be compared to the serum concentration in the human. Moreover, as embryos can also be cultured directly on human serum, it may serve as a tool to investigate the direct effects of sera from women with different diseases on embryonic development. Additionally, the early somite rat embryo culture model can allow the evaluation of success of various treatment modalities and thus may be an important tool to predict the outcome of the pregnancy. This can be achieved due to the yolk sac (the chorioallantoic placental equivalent at this stage in rat pregnancy) which provides a large surface area for nutritional and respiratory exchange between the embryo and the culture medium. Previous studies proved that rat conceptuses explanted at 9.5-12.5 days, when the embryo develops from the early neurula to the late tail bud stage, can be maintained in vitro for 48 hours with almost $100 \%$ survival and growth that is indistinguishable from that occurring in vivo.

The technology in brief: Pregnant female rats are euthanized on day 9.5 to 12.5 of pregnancy when sperm finding is considered to be day 0 . The embryos are cultured for $28-48$ hours at 
$37^{\circ} \mathrm{C}$ in rotating bottles, and supplemented with gas mixtures: day- $1: 20 \%$ Oxygen, $75 \% \mathrm{~N} 2$, $5 \%$ CO2, and day-2: $40 \%$ oxygen, $55 \%$ N2, and 5\% CO2. After 28-48 hours of culture the embryos are examined under a dissecting microscope and scored according to the method described by Brown et al (Brown \& Fabro, 1981) and us (Abir \& Ornoy, 1996, Abir et al., 1994). Only embryos with a beating heart are examined for yolk sac size and circulation, axial rotation, neural tube closure, presence of telencephalic vesicles, optic and otic vesicles, number of somites, body size, and presence of gross anomalies. The use of morphological scoring system provides an index for embryonic development proportional to the embryonic age and aids in the detection of anomalies induced by the different teratogens. The embryos and yolk sacs are kept for different morphological, biochemical and molecular studies.

The possible direct effects of the sera from women with autoimmune diseases can be examined on cultured rat embryos using sera or IgG obtained from women with SLE/ APLs as the culture medium, and analyzing the effects these sera has on embryonic growth, rate of anomalies, and ultrastructural yolk sac damage compared to sera from control healthy women and control rats.

\subsection{Human placental explants in culture}

The use of first trimester chorionic villi explants cultures has the advantage over cell culture of being the in vivo source of extravillous trophoblast and the preservation of topological and functional villous-extravillous trophoblast inter-relationships. It was demonstrated that first trimester villous explants maintained on Matrigel or rat tail collagen support the villous explants differentiation, migration and hormone production in 98 per cent of cultures (Genbacev et al., 1992). The study of placental explants in culture, where no blood circulation exists, enabled the evaluation of the direct effects of different sera on the placenta, thus exposing the mechanisms of placental damage other than placental infarcts, thrombosis and vasculopathy.

The technique in brief: Placental tissue of 5.5-7.5 weeks of gestation are transferred on sterile gauze in an ice-cold phosphate-buffered saline and then removed to a Petri dish and rinsed in phosphate buffered saline. Placental tissue is dissected from deciduas and fetal membranes for inspection under a dissecting microscope. Explants of approximately $10 \mathrm{mg}$ wet weight are transferred into Millicell-CM culture dish insert (Millipore, Bedford, MA), which has been previously layered with polymerized Matrigel ${ }^{\circledR}$ (Collaborative Research, Bedford, MA). The inserts are then placed in 24-well culture dishes. Explants are placed in incubator $(5 \% \mathrm{CO} 2)$ for $60 \mathrm{~min}$ at $39^{\circ} \mathrm{C}$ to evaporate phosphate buffered saline droplets to assist in villi adherence to the thin layer of Matrigel ${ }^{\circledR}$. Cultures are incubated overnight in an incubator with 5\% CO2. Twelve hours from the initiation of culture $400 \mu \mathrm{l}$ of different types of different sera enriched with $1 \mathrm{mg}$ glucose $/ \mathrm{ml}$ are added directly to the inserts. Both the media from the insert (top) and the well (bottom) are changed every $48 \mathrm{hr}$, collected, and stored at $-20^{\circ} \mathrm{C}$ until assayed. Villous explants are inspected daily using an inverted phasecontrast microscope for general cellular integrity, cellular proliferation, and outgrowth. The explants remain in culture for 4 days. At the end of the experiment, villi with supporting Matrigel ${ }^{\circledR}$ are dissected out using surgical blades and kept for morphological, immunohistochemical biochemical and molecular studies, and the media is removed for the analysis of major hormones secreted by the placental tissue.

To evaluate the possibility that in SLE/APLs at least some of the antibodies may directly damage placental trophoblastic cells, consequently causing fetal damage that may lead to 
intrauterine growth restriction or fetal death and to evaluate therapeutic interventions we used human placental explants in culture.

\section{In vitro studies of embryotoxicity of sera from women with recurrent abortions on pre-implantation mice in culture}

\subsection{The embryotoxicity of sera from women with recurrent abortions on pre- implantation mice in culture}

Mouse blastocysts 3.5-day-old at late morula stage and inside the zona pellucida, were cultured for $72 \mathrm{~h}$ in $50 \%$ or $80 \%$ sera from women with recurrent abortions. In embryos cultured in sera from women with recurrent abortions, 53.2\% did not reach blastocystic development, compared to $33.6 \%$ of the embryos grown on sera from women after only one miscarriage and $8.2 \%$ and $12 \%$ on control sera from women following delivery of a normal infant or on sera obtained from women in the second trimester of a normal pregnancy respectively. When sera from women with miscarriages were divided into "high risk" (50\% or more embryotoxicity) and "low risk" (less than 50\% embryotoxicity) sera, the "high risk" sera from two or more miscarriages caused an average of $72.1 \%$ undevelopment (i.e. not reaching the blastocystic stage), while the "low risk" sera from the same group caused 33.6\% undevelopment. The "high risk" sera from one miscarriage were embryotoxic to $55.8 \%$ of the blastocysts and the "low risk" sera from the same group caused only $8.7 \%$ undevelopment similar to the controls (Abir et al., 1990).

\subsection{The limitations of the pre-implantation rat culture}

The limitations of this method is that it is impossible to evaluate even early postimplantation periods that equivalents early organogenesis. It cannot be used for the study of growth restriction and for the effects of teratogens which affect the embryo in later stage. In addition, the small embryonic size limits the possibility to perform various biochemical and genetic studies and does not allow the investigation of the effect of the different chemicals on isolated organs.

In conclusion: More pre-implantation mouse blastocytes failed to reach blastocystic development when cultured in sera obtained from women with recurrent abortions compared to those cultured in control sera.

\section{In vitro studies of the embryotoxicity of sera from patients suffering from systemic lupus erythematosus/antiphospholipid syndrome on early somite rat embryos in culture}

\subsection{The role of IgG antibodies in recurrent abortions}

To test the hypothesis that IgG antibodies from women with recurrent abortions may be responsible for the miscarriage, sera from women one day after an abortion were used as culture media for 10.5 days old embryos and compared to human control sera obtained from women either during a second trimester of a normal pregnancy or a day after normal delivery. Anomalies rate increased from $22 \%$ among controls to $47 \%$ among embryos cultured in sera from women who had a history of one abortion and to $54 \%$ among embryos cultured in sera from women who had a history of two abortions or more. Anomalies 
included mainly microcephaly, open neural tube, lack of eyes and cardiac anomalies. The difference between the sera was more prominent when the sera were classified as low- less than $50 \%$ anomalies compared to high-more than $50 \%$. The high rate of anomalies was particularly characteristic to the highly teratogenic sera while in the other sera anomalies rate was similar to controls. This difference may indicate a basic difference between the two sera groups: one that has a factor(s) that is teratogenic in this model and the other that induces abortions in a different mechanism that is not relevant to this model.

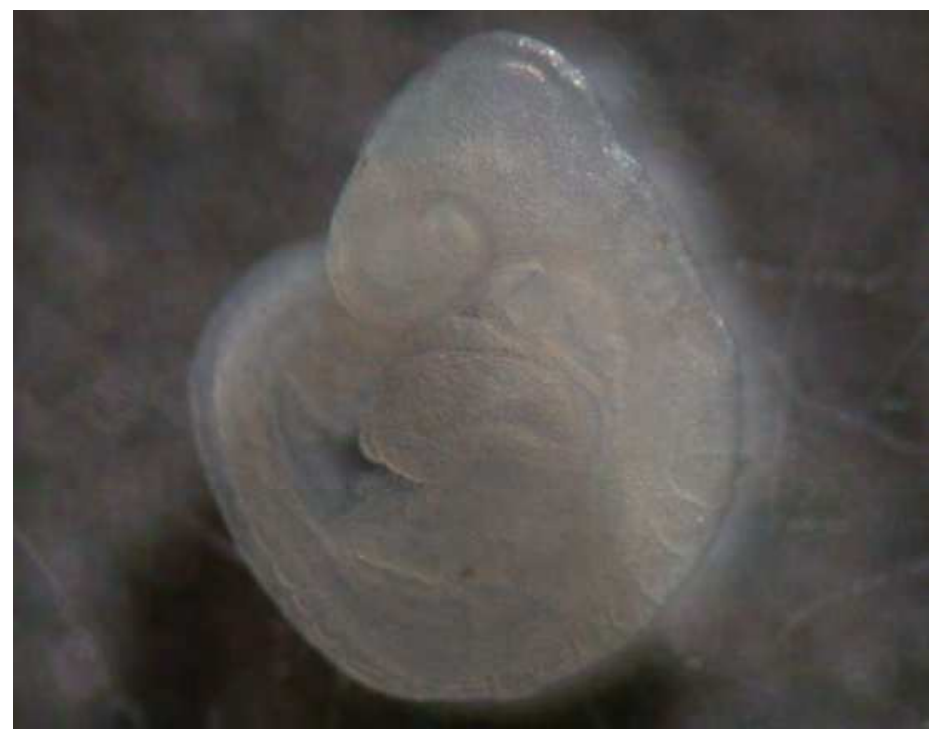

Fig. 1. Early somite 10.5 days rat embryo after 28 hours in culture: normal embryo

To further evaluate whether the embryotoxic factor in this model is IgG, we used high risk sera and control sera, separated the IgG fraction and exchanged it between the sera. We defined three groups: one in which IgG from controls corrected the anomalies induced by the toxic sera, and the IgG from toxic sera induced anomalies in the embryos cultured in the control sera, the second in which control sera did not reduce the rate of anomalies but the IgG induced anomalies in the controls, and the third in which no effect was demonstrated after IgG exchange. We assumed that in these embryos a different factor was responsible for the teratogenicity. When the yolk sacs were evaluated by transmission electron microscopy we found a morphological damage represented by fewer microvilli and more inclusions in the entodermal epithelial cell in the sacs from embryos cultured in high risk sera (Abir et al., 1993).

\subsection{The role of IgG antibodies in intra-uterine growth restriction}

Besides recurrent abortions and fetal death, a main morbidity among infants of mothers suffering from autoimmune diseases is intra-uterine growth restriction. To investigate the role of the IgG antibodies on embryonic and fetal growth we evaluated the effect of high levels of antiphospholipid and anti DNA antibodies on 11.5 days rat embryos in culture, a stage when most of the organs have already been formed. Reduced fetal growth and yolk 


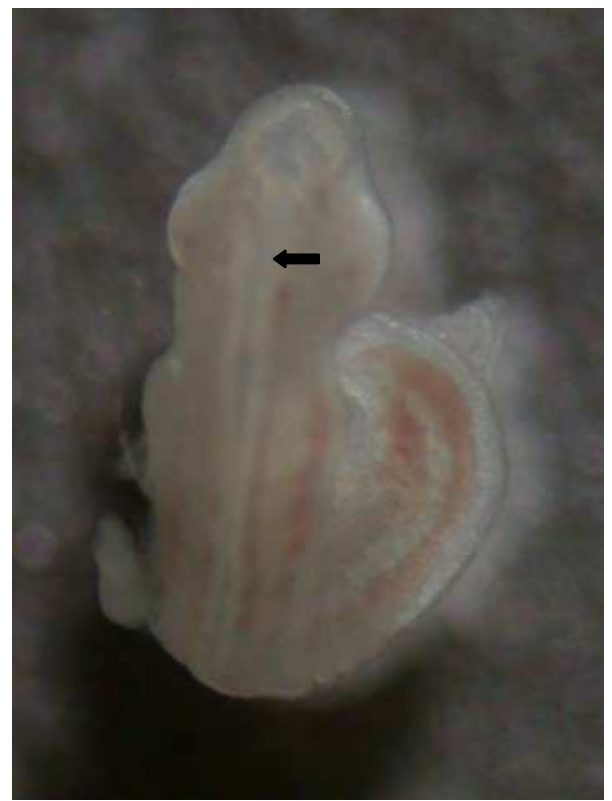

Fig. 2. Early somite 10.5 days rat embryo after 28 hours in culture: arrow-open neural tube

sac diameter were found in embryos cultured in media containing IgG from women suffering from SLE / recurrent abortions, compared to IgG from controls or medium without IgG. When we evaluated the role of the different IgG fractions (anticardiolipin- $\beta 2$ glycoprotein, antiphosphatidylserine, anti-double stranded DNA, anti-laminin, antithyroglobulin and anti-pyruvate dehydrogenase) compared to controls, only embryos that were cultured in sera positive for anti-cardiolipin were significantly smaller than the embryos cultured in sera containing normal IgG fractions. The embryos cultured in medium containing anticardiolipin/ anti DNA/ antiphosphatidylserine had a smaller yolk sac. However, embryos cultured in sera from SLE patients with a history of recurrent abortions were also smaller even when they were negative for antiphosphatydilserine. In spite of the fact that in these experiments the embryos were cultured towards the end of organogenesis when many of the organs have already been formed, $15.6 \%$ of the embryos exposed to IgG purified from women suffering from SLE / recurrent abortions had anomalies, while only $8.7 \%$ of the embryos exposed to IgG purified from sera of healthy women were malformed. There was a significant difference in the development of the brain and branchial bars between embryos that were exposed to patients' IgG and those exposed to IgG that was purified from healthy women. There was also a significant reduced somite number among the experimental group embryos (Matalon et al., 2002).

\subsection{The effect of IgG antibodies on the yolk sac}

The embryos at the early somite stage are surrounded by their yolk sac and by their ectoplacental cone which is the trophoblastic part of the cellular complex at the embryonic pole of the blastocyst. The ectoplacental cone is responsible for the invasion into the decidua. To evaluate the mechanism by which IgG affects the yolk sac, 11.5 days old embryos were cultured in two human IgG2 monoclonal antiphosphatidylserine antibodies 
(HL5B, RR7F). The antiphosphatidylserine antibodies were associated with implantation failure in previous studies with mainly trophoblastic injury by inhibition of syncytium formation, decreased human chorionic gonadatropin (hCG) production, and disturbed trophoblast invasion (McIntyre, 2003). The HL5B monoclonal antibody was generated from a primary antiphospholipid syndrome patient with multiple central ischemic events and the RR7F monoclonal antibody was generated from SLE patient with high titers of circulating antiphosphatidylserine and anticardiolipin antibodies, with no history of thrombosis or fetal loss. Both antibodies showed reactivity against phosphatidylserine and cross-reactivity with cardiolipin but lacked reactivity against $\beta 2$-glycoprotein and did not have a lupus anticoagulant activity. Embryos cultured in both sera had reduced yolk sac diameter without significant difference in the rate of anomalies. Apoptotic processes were found in some of the giant cells and in most of the cells located in the area between the mature giant cells to the small cytotrophoblastic mononuclear cells. More apoptotic cells were counted within the ectoplacental giant cells exposed to anti phosphatidylserine in comparison with cells that were exposed to the control human IgG. More than $19 \%$ of the giant cells that were exposed to HL5B (from the patient with multiple ischemic events) underwent apoptosis, while only $12.7 \%$ of the cells exposed to RR7F (from the patient with high titers of circulating antiphosphatidylserine and anticardiolipin, with no thrombosis neither fetal loss) and 7.3 and $9.6 \%$ of the cells exposed to the control IgG or the experimental medium alone underwent apoptosis. Both antibodies stained the ectoplacental cone in the rat embryos most strongly with the moderately larger cell layer. Cytotrophoblastic mononuclear cells, which are located in the center of the ectoplacental cone, were not stained. The control antibodies did not stain the ectoplacental cone at all. Immunofluorescence staining proved that the anti phosphatidylserine monoclonal antibodies, reacted with 11.5-day ectoplacental cone cells (Matalon et al., 2004).

\subsection{The embryotoxicity of oxidative stress}

The role of oxidative damage in disease activity among patients suffering from autoimmune diseases has become more evident in the last decade (Wang et al., 2010). Reactive Oxygen Species (ROS) have been implicated in causing immunogenic modifications in the DNA and causing oxidative damage that may lead to various autoimmune and degenerative diseases. Excessive ROS production which disturbs redox status, may damage macromolecules and modulate the expression of a variety of immune and inflammatory molecules leading to inflammatory processes and affecting tissue damage (Nathan, 2002).

The role of oxidative stress in SLE was demonstrated in various studies including: an association of the oxidative stress parameters with the pro-inflammatory cytokines (Shah et al., 2011b); exposure of purified human dsDNA resulting in ROS production that led to changes in the primary structure of the dsDNA that rendered it highly immunogenic when injected into rabbits (Al Arfaj et al., 2007); a positive correlation between apoptotic cell numbers and ROS production and increased numbers of apoptotic cells positively correlating with lipid peroxidation in SLE patients (Shah et al., 2011a). The Conflicting results on antioxidant enzyme activities may be due to continued oxidative stress and measurement of different components of the antioxidant system at different disease stages (Ames et al., 1999, Whitaker \& Knight, 2008, Zaken et al., 2000). However the role of oxidative stress in recurrent fetal death and growth restriction is unclear.

Despite medical treatment, women with autoimmune diseases suffer from increased rate of pregnancy complication. We tried to determine if during remission there is a relation between 
the clinical history of the SLE patients (i.e. recurrent abortions and/or thromboembolic event) and the morphologic and functional damage which their sera induce on the 10.5 days rat embryos and yolk sac in culture. We used as culture media sera from SLE / APLs patients during remission (The APLs patients were at least one year free of clotting events and the SLE patients had SLEDAI (Systemic lupus erythematosus disease activity index-a commulative clinical and laboratory index with higher scores representing increased disease activity) 2000 less than 4 and compared it to control human sera. The survival of the embryos cultured in sera of SLE / APLs women decreased significantly from $87.5 \%$ to $70.9 \%$ in comparison to embryos cultured in control sera. There was a positive correlation between survival rate, the neurological developmental stage (calculated by summing the score given for the caudal neural tube, hind, mid and forebrain) and number of somites. Additionally a significant positive correlation between the growth parameters was demonstrated among the embryos cultured in sera from patients and controls: the larger embryos had larger yolk sacs; had higher general and neurologic developmental score and more somites, implying more mature embryos. (Ergaz et al., 2010). A high rate of anomalies in embryos cultured in sera from women with recurrent spontaneous abortions (Abir et al., 1994) or following the addition to the culture medium of purified IgG from SLE and APLs patients (Abir \& Ornoy, 1996), differed from the study using sera obtained from non-pregnant patients in remission, where there was no increase in the rate of anomalies compared to controls. It can be speculated therefore, that the teratogenicity of the sera reflected the patient's high-activity disease state (Clowse et al., 2005). Delayed neurological system development when the brain structures development were behind the other embryonic systems was the predominant finding in correlation with clinical studies published in the medical literature that reported learning and memory impairment among offspring of mothers with SLE (Urowitz et al., 2008, Ross et al., 2003) and the finding that the main anomalies in our previous studies were neural tube defects (Abir et al., 1994). We speculate that the low activity of the disease allowed high survival and low anomalies rate in most of the sera but some sera remained teratogenic due to factors that were still active despite remission. We defined two sera groups: "toxic" sera with over-all survival rate under $2 / 3$ and those cultured in "non-toxic" sera with over-all survival above $2 / 3$. In order to define the characteristics of the "toxic" sera we analyzed the correlations between the survival rate, the growth parameters, maternal laboratory findings regarding APLs and the clinical history of the patients. We did not find a correlation between sera toxicity and: the diagnosis of APLs; The levels of the specific antibodies (anti-double stranded DNA, anti-single stranded DNA and the antiphospholipid antibodies: anti cardiolipin, anti- $\beta 2$ glycoprotein, antiphosphatidylserine, antiphosphatidylcholine and antiphosphatidylethanolamine) which were high compared to human controls. There was no significant correlation between the survival rate and any specific antibody measured in those sera, the history of recurrent abortions and toxemia and the history of thrombo-embolic attacks. The yolk sac function was evaluated by measuring the $14 \mathrm{C}$ sucrose endocytic index which did not differ between the controls and SLE/APLs non toxic sera, this is explained by the fact that we studied the index only in "non toxic" sera.

To evaluate the antioxidant defense mechanisms which include a variety of intracellular enzymes we evaluated superoxide dismutase, catalase like activity, and low molecular weight antioxidants. The low molecular weight antioxidants includes lypophilic and hydrophilic molecules like glutathione, carnosine, ascorbate (vitamin C), tocopherol (vitamin E), carotenoids (vitamin A), bilirubin, uric acid and flavonoids, which act directly with various reactive oxygen species, DNA repair enzymes and methionine sulphoxide 
reductase that repair or remove reactive oxygen species-damaged biomolecules (Ornoy et al., 1999). Our previous studies on the reducing power of the low molecular weight antioxidants in control rat embryos and yolk sacs revealed only one peak 1 at 560-620 mvolts on 9.5-11.5 days of gestation and an additional peak (peak 2) at 950-970 mvolts first appearing on day 11.5 of gestation (Zaken et al., 2000), which is the day we ended our culture. The major components of peak 1 as measured by HPLC are ascorbic and uric acids, Tryptophan, carnosine, melatonine (Beit-Yannai et al., 1997) and thioacetic acid (Chevion et al., 2000) were found to be the major components of peak 2 in the rat brain. The low molecular weight antioxidants were evaluated by cyclic voltametry (Zaken et al., 2000). Most of the embryos cultured in the "toxic" SLE / APLs sera did not have the peak 2 of the low molecular weight antioxidants. The lack of the peak 2 in the present study may be the reflection of the delayed embryonic maturation as the embryos were smaller and less developed. This is similar to our finding of decreased low molecular weight antioxidants demonstrated by the absence of peak 2, in 10.5 days embryos cultured for 28 hours under diabetic conditions (Zaken et al., 2000). There was also a positive correlation between a lower peak 1 of low molecular weight antioxidants and recurrent abortions in the embryos cultured in the SLE / APLs sera that was not related to sera toxicity. Catalase and superoxide dismutase activity did not vary between the groups. It is unknown whether the oxidative insult has a similar effect on the different developing organs. We evaluated the oxidative stress in the total embryo, while the different organs and systems in the rat embryo may have different expressions under similar circumstances (Dubnov et al., 2000). The normal levels of the anti oxidant enzymes evaluated may indicate that sera toxicity is not related to oxidative stress. We did not find any past clinical history or laboratory finding that was in correlation with the sera embryotoxicity. The possible causes for the high embryotoxicity of about half of the sera in remission are currently unknown.

\subsection{The effect of maternal medical treatment on sera teratogenicity}

The role of some treatment modalities was evaluated by rat embryo cultures in sera from women with and without medications. We examined 10.5 days old embryos cultured in sera from women suffering from SLE complicated by recurrent abortions, either untreated women, or treated with steroids and aspirin and compared the results to embryos cultured in sera from control women and to a pool of control rat sera. Untreated sera resulted in $45.1 \%$ death rate compared to $29.8 \%$ in treated sera, $3.9 \%$ in control human and $5.1 \%$ in control rat serum. Malformation rate decreased from $73.3 \%$ in untreated sera to $37.5 \%$ in treated sera, $10.2 \%$ in human controls and $5.4 \%$ in rat controls. Malformations were mostly in the heart, brain, limbs and tail (Ornoy et al., 1998). Thus, treatment that improves pregnancy outcome also reduces the embryotoxic effects of the sera.

\subsection{The effect of maternal medical treatment on the extent of yolk sac damage}

Transmission electron microscopy of the yolk sacs revealed an increase in intracellular inclusions and decrease in microvilli number in both experimental groups, embryos cultured in sera from treated or untreated patients compared to controls. Scanning electron microscope revealed abnormally large entodermal cells, a decreased number of microvilli with sometimes crater formation (Ornoy et al., 1998). The anticoagulant treatment reduced fetal anomalies rate but did not improve yolk sac damage implying that yolk sac damage is only a component in the different factors leading to fetal damage. 


\subsection{The limitations of the early somite rat embryo culture system}

By using the early somite rat embryo culture system we evaluated the direct effect of sera from patients suffering from autoimmune diseases and analyzed the levels of the different sera variables during flare and remission. The impact of the different sera was not universal, and only some of the sera caused embryonic damage. Since the antiphospholipid antibodies were proven as the cause of embryotoxic effect only in some of the sera, we believe that other mechanisms are involved in the teratogenic effect and growth restriction as well. A disadvantage of this in vitro testing are also the limited culture time and limited period of embryogenesis that is undertaken in the commonly used culture system which restricts the range of embryotoxicity that can be induced. It may, therefore, render the testing system unsuitable for teratogens that are likely to exert their major toxicological effect very early or late in gestation (Webster et al., 1997). Additionally we evaluated embryonic growth, structural anomalies and yolk sac function. Infants of mothers who suffer from SLE experience mainly intra-uterine growth retardation, which may be more prominent at the final pregnancy stages not in correlation with the pregnancy stage of early somite rat embryos. The lack of change in oxidative stress parameters may reflect the evaluation of the embryo as a whole. It is unknown whether the oxidative insult has a similar effect on the different developing organs. The different organs and systems in the rat embryo may have different expressions under similar circumstances as shown in another murine model (Dubnov et al., 2000).

In conclusion: Early somite rat embryos cultured in sera from women who suffered from autoimmune diseases had lower survival rate, increase anomalies rate and delayed maturation as reflected by their lower morphological score and less developed anti-oxidant system. The damage was related to IgG antibodies only in some of the embryos. Morphologic yolk sac damage was constant and did not improve with maternal medical treatment.

\section{Placental explants studies}

\subsection{The effect of SLE/APLs sera on placental explants}

At the early somite stage the yolk sac is the equivalent of the human chorioallantoic placenta. The inhibition of yolk sac growth even without inhibition of embryonic growth, as well as ultrastructural damage to the yolk sac endothelial cells may indicate that the primary insult or at least a major insult in SLE / APLs and recurrent abortions may be damage to the placenta.

We therefore examined the effects of sera from the patients on early human placental explants obtained from interruptions of normal 5.5 to 7.5 week-old pregnancies (because of psychosocial reasons), and compared to the effects of sera from healthy women and of a chemically defined medium. Placental explants cultured on sera from untreated non-pregnant women with SLE/APLs demonstrated a significant decrease in the trophoblastic cell proliferation rate compared with non-pregnant control women (Ornoy et al., 2003). Placental extracts cultured in SLE/APLs had a higher rate of apoptosis, and reduced $\beta$ hCG secretion in correlation with antiphospholipid antibodies levels. The sera were analyzed for the presence and quantification of anti-double stranded DNA, anti-single stranded DNA and antiphospholipid antibodies (anti cardiolipin, anti- $\beta 2$ glycoprotein, antiphosphatidylserine, antiphosphatidylcholine and antiphosphatidylethanolamine) and Anti-Ro and anti-La. High levels of all the different antiphospholipid atibodies and both anti-dsDNA and anti-ssDNA 


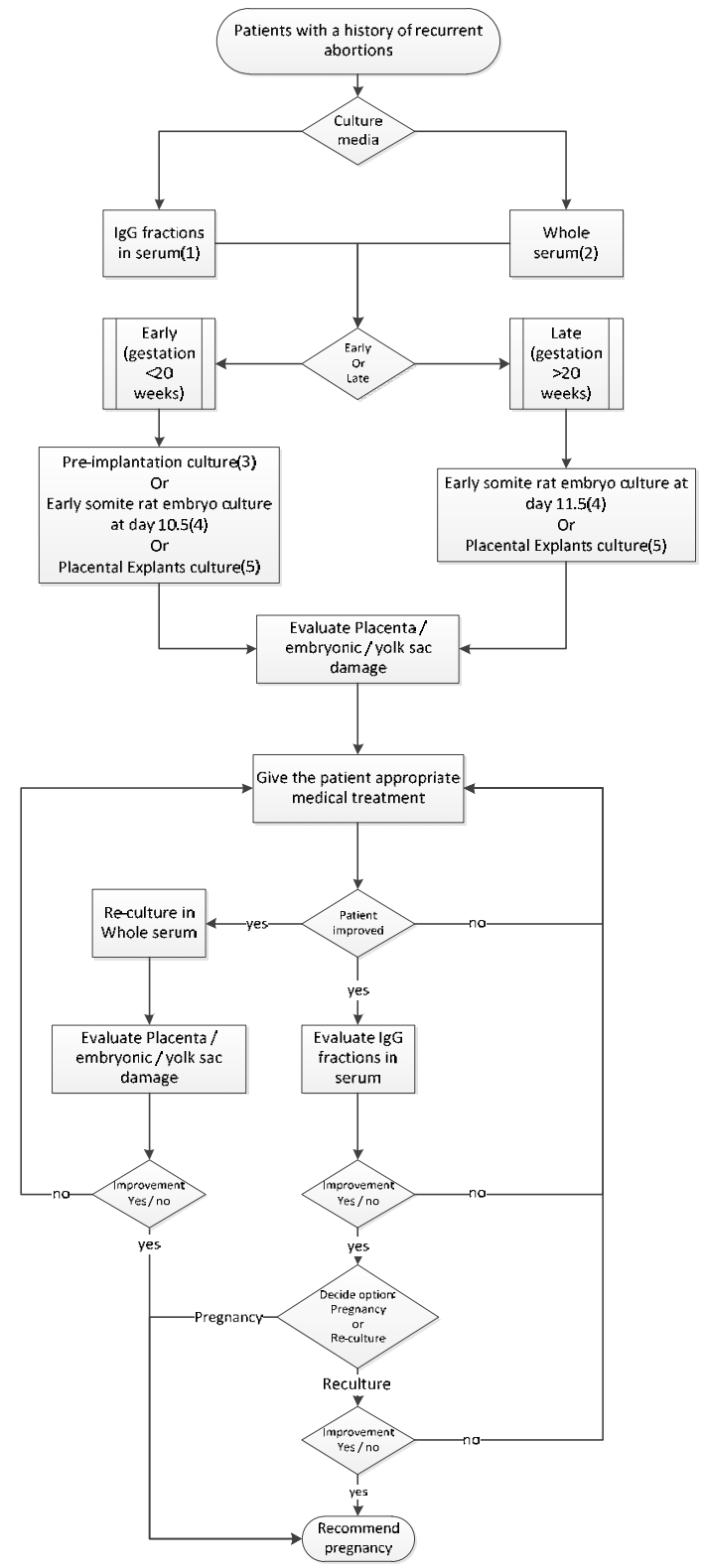

(1) More specific, embryotoxic in $2 / 3$ of the sera.

(2) Less specific but allows to investigate the multi factorial mechanisms of embryotoxicity.

(3) Evaluate blastocystic development.

(4) Evaluate: Embryonic survival, score, anomalies rate and yolk sac apoptosis.

(5) Evaluate trophoblastic cell proliferation, apoptosis and $\beta$ hCG secretion.

Fig. 3. In vitro cultures as an aid in clinical decisions making for recurrent abortions 
showed a trend towards reduction in $\beta$ hCG secretion by the placental extracts in culture. Titers of anti-Ro and anti-La did not correlate with a reduction in the $\beta$ hCG levels, probably because anti-Ro and anti-La antibodies exert their effect on pregnancy by a passively transferred autoimmune disease in fetuses or newborns, causing neonatal lupus and not through placental damage. There was no specific single antibody that could be identified to cause the placental damage, but rather a combination of different antibodies was responsible for the cumulative damage, in accordance with the inconsistent findings of the effects of the different antiphospholipid antibodies (Schwartz et al., 2007).

\subsection{The effect of maternal medical treatment on the degree of damage induced in placental explants}

When we evaluated the impact of maternal treatment with steroids and/or aspirin on placental explants, treatment significantly increased proliferation rate compared with the untreated group but remained significantly lower than that found in the control nonpregnant women. Additionally, a significant increase in the rate of the trophoblastic cell apoptosis was demonstrated compared to explants cultured in sera from treated or control women. The apoptotic rate, however, was still significantly higher in the treated group than that found in the control human group (Yacobi et al., 2002).

\subsection{The limitations of the placental explants culture system}

The placental explants system allows the investigation of the direct effect of sera on trophoblastic proliferation. This system where only young human placental explants are cultured does not seem to enable the investigation of late pregnancy damage induced by the various mechanisms. Additionally it does not allow the investigation of growth parameters which tend to impact the fetus at later pregnancy stages.

In conclusion: Placental explants culture in SLE/APLs sera had decreased trophoblastic cells proliferation, a higher rate of apoptosis, and reduced $\beta$ hCG secretion in correlation with antiphospholipid antibodies levels, and increased yolk sac trophoblastic cell apoptosis.

\section{Conclusions}

The pathophysiology of fetal loss and growth restriction among patients suffering from SLE/APLs is still an open question that needs to be studied. The pre-implantation murine and early somite rat embryo culture offers a model for evaluation of the direct effect of the different antibodies and molecules on survival and growth at different time points during pregnancy. The concomitant evaluation of the yolk sac function allows the investigation of those molecules on the rodent's placental equivalent. The addition of the human early placental extracts culture improves the understanding of the disturbance to early placental differentiation, migration and hormone production induced by similar teratogens.

\section{Future research possibilities}

New molecules associated with fetal death, embryotoxicity and growth failure were discovered in the last years. The direct effect of those molecules can be evaluated in vitro on placental explants, murine pre-implantation embryos and on early somite rat embryos in culture in order to isolate the impact that each molecule has, solely or in combination with other molecules on pregnancy outcome. The evaluation of the pathological, immunological 
and biochemical parameters of the cultured embryos may add more clues to the multifactorial mechanism of fetal damage among women suffering from autoimmune diseases. The understanding of those mechanisms may help to develop new treatment modalities which can also be evaluated in this model.

\section{References}

Abir R, Zusman I, Ben Hur H, Yaffe P, \& Ornoy A. The effects of serum from women with miscarriages on the in vitro development of mouse preimplantation embryos. Acta Obstet Gynecol Scand. 1990;69(1):27-33.

Abir R, Ornoy A, Ben Hur H, Jaffe P, \& Pinus H. IgG exchange as a means of partial correction of anomalies in rat embryos in vitro, induced by sera from women with recurrent abortion. Toxicol In Vitro. 1993 Nov;7(6):817-26.

Abir R, Ornoy A, Ben Hur H, Jaffe P, \& Pinus H. The effects of sera from women with spontaneous abortions on the in vitro development of early somite stage rat embryos. Am J Reprod Immunol. 1994 Sep;32(2):73-81.

Abir R, \& Ornoy A. Teratogenic IgG from sera of women with spontaneous abortions seem to induce anomalies and yolk sac damage in rat embryos. A possible method to detect abortions of immunologic origin. Am J Reprod Immunol. 1996 Feb;35(2):93-101.

Al Arfaj AS, Chowdhary AR, Khalil N, \& Ali R. Immunogenicity of singlet oxygen modified human DNA: implications for anti-DNA antibodies in systemic lupus erythematosus. Clin Immunol. 2007 Jul;124(1):83-9.

Alijotas-Reig J, Palacio-Garcia C, \& Vilardell-Tarres M. Circulating microparticles, lupus anticoagulant and recurrent miscarriages. Eur J Obstet Gynecol Reprod Biol. 2009 Jul;145(1):22-6.

Ames PR, Alves J, Murat I, Isenberg DA, \& Nourooz-Zadeh J. Oxidative stress in systemic lupus erythematosus and allied conditions with vascular involvement. Rheumatology (Oxford). 1999 Jun;38(6):529-34.

Beit-Yannai E, Kohen R, Horowitz M, Trembovler V, \& Shohami E. Changes of biological reducing activity in rat brain following closed head injury: a cyclic voltammetry study in normal and heat-acclimated rats. J Cereb Blood Flow Metab. 1997 Mar;17(3):273-9.

Brown NA, \& Fabro S. Quantitation of rat embryonic development in vitro: a morphological scoring system. Teratology. 1981 Aug;24(1):65-78.

Chen LT, \& Hsu YC. Development of mouse embryos in vitro: preimplantation to the limb bud stage. Science. 1982 Oct 1;218(4567):66-8.

Chevion S, Roberts MA, \& Chevion M. The use of cyclic voltammetry for the evaluation of antioxidant capacity. Free Radic Biol Med. 2000 Mar 15;28(6):860-70.

Clowse ME, Magder LS, Witter F, \& Petri M. The impact of increased lupus activity on obstetric outcomes. Arthritis Rheum. 2005 Feb;52(2):514-21.

Cohen D, Buurma A, Goemaere NN, Girardi G, le Cessie S, Scherjon S, et al. Classical complement activation as a footprint for murine and human antiphospholipid antibody-induced fetal loss. J Pathol. 2011 Mar 10.

Dubnov G, Kohen R, \& Berry EM. Diet restriction in mice causes differential tissue responses in total reducing power and antioxidant compounds. Eur J Nutr. 2000 Feb;39(1):18-30.

Ergaz Z, Mevorach D, Goldzweig G, Cohen A, Patlas N, Yaffe P, et al. The embryotoxicity of sera from patients with autoimmune diseases on post-implantation rat embryos in 
culture persists during remission and is not related to oxidative stress. Lupus. 2010 Dec;19(14):1623-31.

Genbacev O, Schubach SA, \& Miller RK. Villous culture of first trimester human placenta-model to study extravillous trophoblast (EVT) differentiation. Placenta. 1992 SepOct;13(5):439-61.

Gharavi AE, Vega-Ostertag M, Espinola RG, Liu X, Cole L, Cox NT, et al. Intrauterine fetal death in mice caused by cytomegalovirus-derived peptide induced aPL antibodies. Lupus. 2004;13(1):17-23.

Halperin R, Elhayany A, Ben-Hur H, Gurevich P, Kaganovsky E, Zusman I, et al. Pathomorphologic and immunohistochemical study on the devastation of rat embryos by antiphospholipid antibody positive serum. Am J Reprod Immunol. 2008 Dec;60(6):523-8.

Kwok LW, Tam LS, Zhu T, Leung YY, \& Li E. Predictors of maternal and fetal outcomes in pregnancies of patients with systemic lupus erythematosus. Lupus. 2011 May 4.

Lee JY, Huerta PT, Zhang J, Kowal C, Bertini E, Volpe BT, et al. Neurotoxic autoantibodies mediate congenital cortical impairment of offspring in maternal lupus. Nat Med. 2009 Jan;15(1):91-6.

Levy RA, Avvad E, Oliveira J, \& Porto LC. Placental pathology in antiphospholipid syndrome. Lupus. 1998;7 Suppl 2:S81-5.

Matalon ST, Shoenfeld Y, Blank M, Yacobi S, Blumenfeld Z, \& Ornoy A. The effects of IgG purified from women with SLE and associated pregnancy loss on rat embryos in culture. Am J Reprod Immunol. 2002 Nov;48(5):296-304.

Matalon ST, Blank M, Matsuura E, Inagaki J, Nomizu M, Levi Y, et al. Immunization of naive mice with mouse laminin-1 affected pregnancy outcome in a mouse model. Am J Reprod Immunol. 2003 Aug;50(2):159-65.

Matalon ST, Shoenfeld Y, Blank M, Yacobi S, von Landenberg P, \& Ornoy A. Antiphosphatidylserine antibodies affect rat yolk sacs in culture: a mechanism for fetal loss in antiphospholipid syndrome. Am J Reprod Immunol. 2004 Feb;51(2):144-51.

McIntyre JA. Antiphospholipid antibodies in implantation failures. Am J Reprod Immunol. 2003 Apr;49(4):221-9.

Meroni PL, Gerosa M, Raschi E, Scurati S, Grossi C, \& Borghi MO. Updating on the pathogenic mechanisms 5 of the antiphospholipid antibodies-associated pregnancy loss. Clin Rev Allergy Immunol. 2008 Jun;34(3):332-7.

Nathan C. Points of control in inflammation. Nature. 2002 Dec 19-26;420(6917):846-52.

New DA, Coppola PT, \& Cockroft DL. Comparison of growth in vitro and in vivo of postimplantation rat embryos. J Embryol Exp Morphol. 1976 Aug;36(1):133-44.

Ornoy A, Yacobi S, Avraham S, \& Blumenfeld Z. The effect of sera from women with systemic lupus erythematosus and/or antiphospholipid syndrome on rat embryos in culture. Reprod Toxicol. 1998 Mar-Apr;12(2):185-91.

Ornoy A, Zaken V, \& Kohen R. Role of reactive oxygen species (ROS) in the diabetesinduced anomalies in rat embryos in vitro: reduction in antioxidant enzymes and low-molecular-weight antioxidants (LMWA) may be the causative factor for increased anomalies. Teratology. 1999 Dec;60(6):376-86.

Ornoy A, Yacobi S, Matalon ST, Blank M, Blumenfeld Z, Miller RK, et al. The effects of antiphospholipid antibodies obtained from women with SLE/APS and associated 
pregnancy loss on rat embryos and placental explants in culture. Lupus. 2003;12(7):573-8.

Rand JH, Wu XX, Andree HA, Lockwood CJ, Guller S, Scher J, et al. Pregnancy loss in the antiphospholipid-antibody syndrome--a possible thrombogenic mechanism. N Engl J Med. 1997 Jul 17;337(3):154-60.

Ross G, Sammaritano L, Nass R, \& Lockshin M. Effects of mothers' autoimmune disease during pregnancy on learning disabilities and hand preference in their children. Arch Pediatr Adolesc Med. 2003 Apr;157(4):397-402.

Schwartz N, Shoenfeld Y, Barzilai O, Cervera R, Font J, Blank M, et al. Reduced placental growth and hCG secretion in vitro induced by antiphospholipid antibodies but not by anti-Ro or anti-La: studies on sera from women with SLE/PAPS. Lupus. 2007;16(2):110-20.

Shah D, Aggarwal A, Bhatnagar A, Kiran R, \& Wanchu A. Association between T lymphocyte sub-sets apoptosis and peripheral blood mononuclear cells oxidative stress in systemic lupus erythematosus. Free Radic Res. 2011a May;45(5):559-67.

Shah D, Wanchu A, \& Bhatnagar A. Interaction between oxidative stress and chemokines: Possible pathogenic role in systemic lupus erythematosus and rheumatoid arthritis. Immunobiology. 2011b Apr 13.

Suzuki H, Silverman ED, Wu X, Borges C, Zhao S, Isacovics B, et al. Effect of maternal autoantibodies on fetal cardiac conduction: an experimental murine model. Pediatr Res. 2005 Apr;57(4):557-62.

Tower C, Crocker I, Chirico D, Baker P, \& Bruce I. SLE and pregnancy: the potential role for regulatory T cells. Nat Rev Rheumatol. 2011 Feb;7(2):124-8.

Urowitz MB, Gladman DD, MacKinnon A, Ibanez D, Bruto V, Rovet J, et al. Neurocognitive abnormalities in offspring of mothers with systemic lupus erythematosus. Lupus. 2008;17(6):555-60.

Wang G, Pierangeli SS, Papalardo E, Ansari GA, \& Khan MF. Markers of oxidative and nitrosative stress in systemic lupus erythematosus: correlation with disease activity. Arthritis Rheum. 2010 Jul;62(7):2064-72.

Webster WS, Brown-Woodman PD, \& Ritchie HE. A review of the contribution of whole embryo culture to the determination of hazard and risk in teratogenicity testing. Int J Dev Biol. 1997 Apr;41(2):329-35.

Whitaker BD, \& Knight JW. Mechanisms of oxidative stress in porcine oocytes and the role of anti-oxidants. Reprod Fertil Dev. 2008;20(6):694-702.

Yacobi S, Ornoy A, Blumenfeld Z, \& Miller RK. Effect of sera from women with systemic lupus erythematosus or antiphospholipid syndrome and recurrent abortions on human placental explants in culture. Teratology. 2002 Dec;66(6):300-8.

Zaken V, Kohen R, \& Ornoy A. The development of antioxidant defense mechanism in young rat embryos in vivo and in vitro. Early Pregnancy. 2000 Apr;4(2):110-23. 


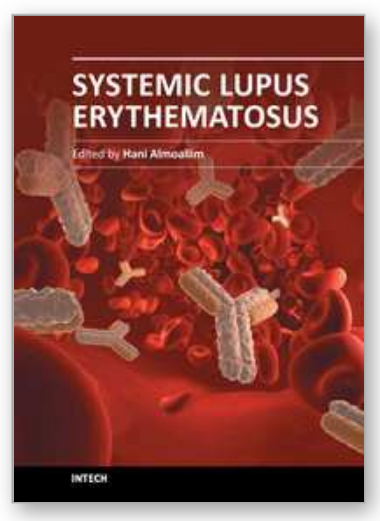

\author{
Systemic Lupus Erythematosus \\ Edited by Dr Hani Almoallim
}

ISBN 978-953-51-0266-3

Hard cover, 554 pages

Publisher InTech

Published online 21, March, 2012

Published in print edition March, 2012

This book provides a comprehensive overview of the basic and clinical sciences of Systemic Lupus Erythematosus. It is suitable for basic scientists looking for detailed coverage of their areas of interest. It describes how advances in molecular biology have increased our understanding of this disease. It is a valuable clinical resource for practicing clinicians from different disciplines including rheumatologists, rheumatology fellows and residents. This book provides convenient access to information you need about cytokines, genetics, Fas pathway, toll like receptors and atherogenesis in SLE. Animal models have been reviewed as well. How to avoid delay in SLE diagnosis and management, in addition to various clinical manifestations including pregnancy and SLE have all been explained thoroughly in this book.

\title{
How to reference
}

In order to correctly reference this scholarly work, feel free to copy and paste the following:

Zivanit Ergaz and Asher Ornoy (2012). Embryonic and Placental Damage Induced by Maternal Autoimmune Diseases - What Can We Learn from Experimental Models, Systemic Lupus Erythematosus, Dr Hani Almoallim (Ed.), ISBN: 978-953-51-0266-3, InTech, Available from: http://www.intechopen.com/books/systemic-lupuserythematosus/embryonic-damage-induced-by-maternal-autoimmune-diseases-an-experimental-rat-model-

\section{INTECH}

open science | open minds

\section{InTech Europe}

University Campus STeP Ri

Slavka Krautzeka 83/A

51000 Rijeka, Croatia

Phone: +385 (51) 770447

Fax: +385 (51) 686166

www.intechopen.com

\section{InTech China}

Unit 405, Office Block, Hotel Equatorial Shanghai

No.65, Yan An Road (West), Shanghai, 200040, China

中国上海市延安西路65号上海国际贵都大饭店办公楼 405 单元

Phone: +86-21-62489820

Fax: +86-21-62489821 
(C) 2012 The Author(s). Licensee IntechOpen. This is an open access article distributed under the terms of the Creative Commons Attribution 3.0 License, which permits unrestricted use, distribution, and reproduction in any medium, provided the original work is properly cited. 